\title{
Extreme reduction in body size and reproductive output associated with sandy substrates in two anuran species
}

\author{
Federico Marangoni $^{1, *}$, Miguel Tejedo ${ }^{1}$, Iván Gomez-Mestre ${ }^{2}$
}

\begin{abstract}
Geographic variation in body size and reproductive traits has been reported in a wide range of organisms, including amphibians. Most studies have focused on latitudinal and/or altitudinal variation where differences in temperature and duration of the growing season are the main causes for population divergence. We describe a steep variation in body size and reproductive traits in two anuran species in southwestern Spain, associated with changes in the geological substrate. Pelobates cultripes and Bufo calamita (= Epidalea calamita) drastically reduced their size (a $71.6 \%$ and $76.1 \%$ reduction in body mass for $P$. cultripes and B. calamita, respectively) in just about $60 \mathrm{~km}$. This extreme size reduction was more pronounced at the boundary between two different geological substrates (hercinic and sandy soil). Mean clutch mass, egg size, and clutch size were all smaller in B. calamita populations in the sandy environment. Likewise, clutch mass and egg size were both smaller in sandy $P$. cultripes populations. We observed a negative correlation between size-adjusted fecundity and egg size for both species, suggesting the existence of a reproductive trade-off that could explain the differences in reproductive allocation between populations and species. In P. cultripes, small-bodied populations had relatively higher fecundities and smaller eggs than large-bodied ones, whereas in B. calamita populations from the sandy area we found both populations with high fecundity and small eggs, and populations with low fecundity and large eggs. Common environmental effects associated with the sandy substrate produce a similar reduction in size in both toad species.
\end{abstract}

Keywords: amphibians, body size, Bufo (= Epidalea) calamita, geographic variation, Pelobates cultripes, reproduction.

\section{Introduction}

Body size is often closely related to fitness due to its association with longevity, fecundity, metabolic rate and tolerance to environmental stresses such as starvation and desiccation (Calder, 1984; Schmidt-Nielsen, 1984). Within-species latitudinal and altitudinal clines in body size are frequently found and are often explained by changes in temperature, duration of the growing season, or a combination of both (Van Voorhies, 1996; Atkinson and Sibly, 1997; but see Mousseau, 1997). In addition to latitudinal and altitudinal clines, instances of dwarfism

1 - Department of Evolutionary Ecology, Estación Biológica de Doñana (C.S.I.C.), Avda. de María Luisa s/n, Pabellón del Perú, 41013, Sevilla, Spain

2 - Department of Wetland Ecology, Estación Biológica de Doñana (C.S.I.C.), Avda. de María Luisa s/n, Pabellón del Perú, 41013, Sevilla, Spain

*Corresponding author; present address: Centro de Ecología Aplicada del Litoral, Consejo Nacional de Investigaciones Científicas y Técnicas, C.C. 291, 3400 Corrientes, Argentina

e-mail: fmarangoni@ebd.csic.es and gigantism have been associated with insular population differentiation in reptiles (Pregill, 1986; Lomolino, 2005; Keogh et al., 2005). Geographical variation in adult female body size may subsequently affect clutch size and offspring size in many organisms, including amphibians (e.g. Tejedo, 1992; Castellano et al., 2004). However, a trade-off between clutch size and offspring size would cause these traits to co-vary since they have important fitness consequences in terms of survival to metamorphosis and population recruitment rates (Semlitsch et al., 1996; Kaplan, 1998).

Most studies of geographical variation in body size and reproductive performance in amphibians have focused on latitudinal and altitudinal variation (Ashton, 2002; Morrison and Hero, 2003; Laugen et al., 2005). Low temperatures experienced at higher latitudes and altitudes result in a lower developmental rate causing larger body size (Atkinson, 1994). However, while it is true that body size variation associated with changes in temperatures exists in amphibians, recently has been demonstrated that 
amphibians do not follow Bergmann's rule of increased size with increased latitude (Adams and Church, 2008). Furthermore, temperature alone fails to fully explain the complex intraspecific patterns of body size variation in amphibians (Ashton, 2002; Adams and Church, 2008). Other factors thus need to be considered in order to explain these diverse patterns in body size.

For terrestrial amphibians that spend most of their time hidden and inactive by burrowing underground, soil environments become a continuous challenge because their permeable tegument constrains water regulation and, therefore, they are forced to maintain a favourable osmotic gradient with the surrounding soil (McClanahan, 1972). For instance, sandy soils have higher water potential and thus a higher propensity to liberate and lose water than other soils. Therefore they can contain less available water under an increasing pressure such as that found during a desiccating dry season (e.g. Ruibal et al., 1969; Cartledge et al., 2006). Previous studies demonstrated that populations of two newt species from a sandy area suffered a drastic reduction in body size compared to populations in non sandy soils (Díaz-Paniagua et al., 1996; Díaz-Paniagua and Mateo, 1999). This pattern of body size reduction may not be limited to newts. If paralleled in other distantly related amphibians with different ecological requirements, it would indicate that common selective pressures occurring in sandy areas produced a similar phenotypic outcome (sensu Endler, 1977). In this study we describe geographical variation in body size and reproductive traits in two toad species, the Iberian Spadefoot Toad (Pelobates cultripes) and the Natterjack Toad (Bufo calamita = Epidalea calamita), along a $120 \mathrm{~km}$ transect in southwestern Spain. The populations studied occupy very different substrates: from sandy soils in the Doñana region (Huelva province) to the old hercinic granite-schist soils of the Sierra Morena (Sevilla province).

\section{Materials and methods}

Populations and study site

We examined the variation in body size and reproductive output of ten populations of $B$. calamita and $P$. cultripes distributed along a $120 \mathrm{~km}$ stretch encompassing two areas with different geological substrates: old hercinic graniteschist soils from Sierra Morena and sandy soils from quaternary aeolian deposits (fig. 1). These sandy soils originated in recent times $(<6500$ years BP) by the filling of the former Guadalquivir river estuary by aeolic deposits, mainly as sand sheets, that became a large system of fixed and mobile dunes that ranges from the coastline to more than $40 \mathrm{~km}$ inland and covers over $2500 \mathrm{~km}^{2}$. We selected four populations from the hercinic soils: Sierra, hereafter; Pedroso (PED), Navas (NAV), Gerena (GER) and Aznalcóllar $(A Z N)$, with a range of altitudes between 100 and $420 \mathrm{~m}$ and five populations from the sandy area: Doñana, hereafter; Lázaro (LAZ), Juncosilla (JUN), Bodegones (BOD), Abalario (ABA) and Reserva Biológica de Doñana (RBD) with a range of altitudes between 20 and $63 \mathrm{~m}$. We also chose a population from a substrate consisting of a mixture of clays and sand, geographically intermediate between the two main geological areas, Sanlúcar (SAN) (fig. 1). All these populations breed in small and shallow temporary ponds that become flooded in the fall and dry up in the summer (Díaz-Paniagua, 1992; Fahd et al., 2000). The main climatic variables did not vary greatly across the transect (annual average rainfall $=640 \mathrm{~mm}$ and $585 \mathrm{~mm}$, temperature $=$ July $25.7^{\circ} \mathrm{C}$ and $24.5^{\circ} \mathrm{C}$, January $9.6^{\circ} \mathrm{C}$ and $10.6^{\circ} \mathrm{C}$, for Navas and RBD populations, respectively, Díaz-Paniagua, 1986; Tejedo and Marangoni, unpublished data).

\section{Body size}

We collected mature individuals from each population and species, from fall 1999 to winter 2004 (B. calamita: $n=670$ and $P$. cultripes: $n=463$ ) across the transect (appendix A). We collected either calling males or pairs in amplexus during chorusing nights between 20:00 pm and 2:00 am, to ensure that all individuals were mature. Toads were separated by sex, placed in independent plastic containers $(49 \times 30 \times 22 \mathrm{~cm})$, and brought to the laboratory. We measured the snout-vent length (SVL) and right hind length (HLR) by placing each toad on laminated graph paper (accuracy $\pm 1 \mathrm{~mm}$ ). We measured body mass (BM), before and after oviposition, to the nearest $0.5 \mathrm{~g}$, using a $100 \mathrm{~g}$ Pesola spring balance. All individuals were released back into their original ponds within $24-48 \mathrm{~h}$ after their capture.

\section{Measurement of reproductive traits}

We collected amplecting pairs from January 1999 to January 2004 (B. calamita: $n=233$ and $P$. cultripes: $n=73$ females). Pairs were separated, isolated by sex in plastic containers $(49 \times 34 \times 22 \mathrm{~cm})$, and brought to an outdoor facility at "La Hampa" field station (IRNA-CSIC). We randomly 


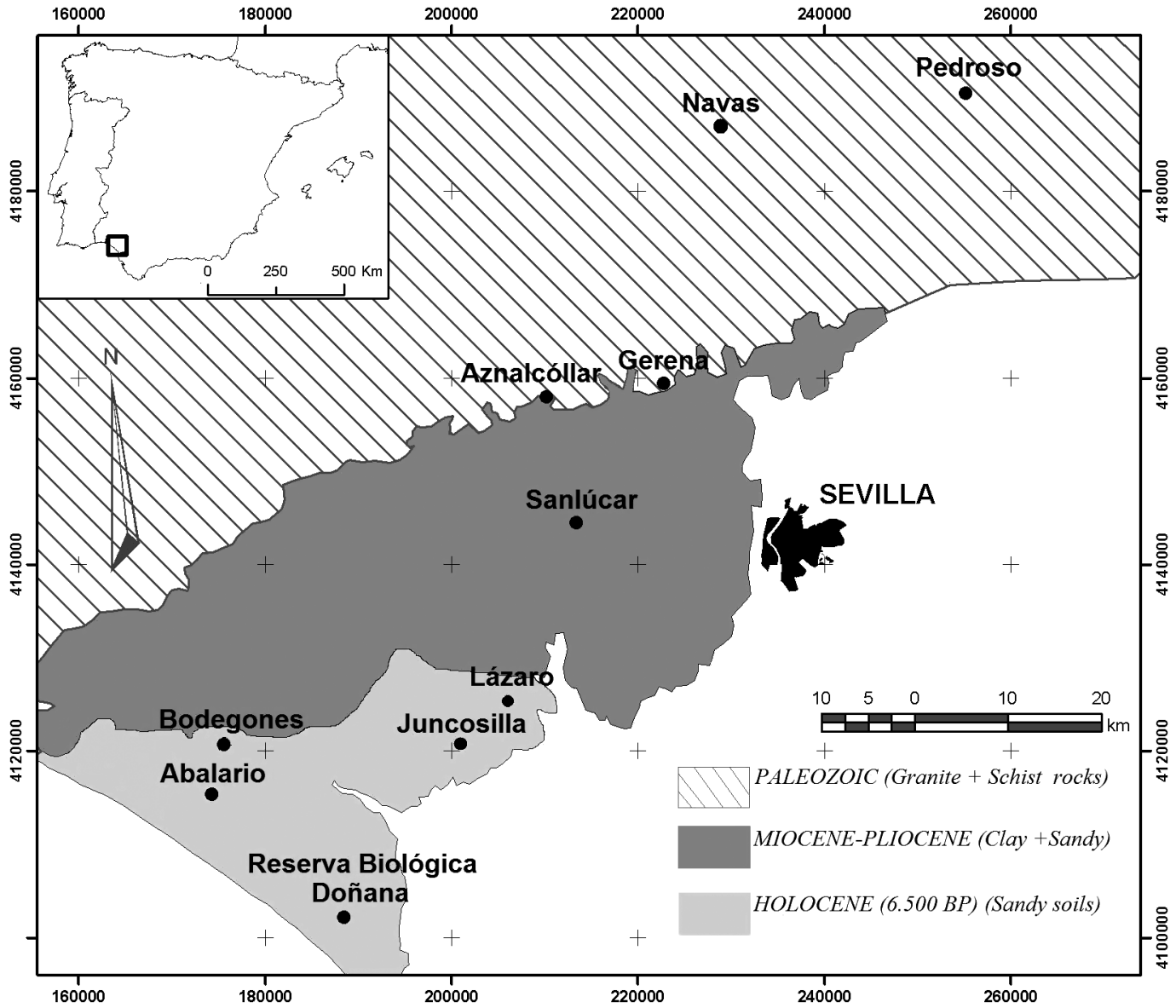

Figure 1. Location and geological substrate of the studied Bufo calamita and Pelobates cultripes populations. Abbreviated names of sampling localities, geographic coordinates (Coordinates UTM x/y in meters, Datum European 1950, Spain and Portugal, Zone: 30), elevation and sample size (Male/Females, B. calamita and P. cultripes, respectively) are as follows: PED (255170/4190574, $395 \mathrm{~m}, n=95 / 56$ and 53/18); NAV (229255/4187617, $420 \mathrm{~m}, n=60 / 6$ and 43/5); GER $(222768 / 4159484,100 \mathrm{~m}, n=22 / 8$ and 3/0); AZN (210199/4158023, $130 \mathrm{~m}, n=0 / 31$ and $0 / 14)$; SAN (213349/4144548, $34 \mathrm{~m}, n=28 / 0$ and 1/0); LAZ (206339/4125928, $20 \mathrm{~m}, n=0 / 18$ and 0/1); JUN (203208/4124509, $23 \mathrm{~m}, n=59 / 0$ and 54/0); BOD (175577/4120711, $32 \mathrm{~m}, n=31 / 43$ and 31/40); ABA $(174267 / 4115417,63 \mathrm{~m}, n=36 / 83$ and 37/69); RBD (188450/4102197, $24 \mathrm{~m}, n=80 / 47$ and 37/24).

assigned pairs to plastic containers $(40 \mathrm{~cm}$ diameter, $33 \mathrm{~cm}$ depth) filled with 10-12 L of well water, where they quickly went back into amplexus. Oviposition took place within $12 \mathrm{~h}$. We photographed the resulting egg clutches with a Digital Video Camera JVC GR-DVX, and obtained counts of the number of eggs in each clutch (clutch size, CS) using Image-Pro Plus 1.1 (Media Cybernetics, 1993-94). Clutch mass (CM) was obtained by subtracting, for each gravid female, her mass after oviposition from her mass prior to it (Tejedo, 1992). We used relative clutch mass (RCM) as an estimate of reproductive effort, calculated as the ratio of clutch mass to spent body mass (Shine, 1992; Bonnet et al., 2003). We also took a random sample of about 30 eggs from each clutch, stored them in $10 \%$ formalin, and later used a micrometer on a dissecting microscope to measure the diameter of 15 eggs per sample to the nearest $0.01 \mathrm{~mm}$.
Egg size (ES) was always measured at Gosner stages 10 and 11 (Gosner, 1960). The remaining eggs from each clutch were returned to their original ponds within $24-48 \mathrm{~h}$ after the adult's capture.

\section{Statistical analyses}

All variables were log-transformed in order to achieve normality, and all analyses were carried out with type III general linear mixed models using the STATISTICA 6.0 statistical package (StatSoft Inc., 2001). We used multi- and univariate analyses of variance to test for differences in body size, body mass and hind limb length between the sexes, between environments (hercinic, sandy) and among populations within environments. Population was considered a random effect throughout the analyses. We used linear regres- 
sions to test the association between female size and clutch characteristics. We then used residual analysis to compare female size-adjusted clutch characteristics across environments and populations.

We found few or no B. calamita females at GER and SAN populations, and few or no $P$. cultripes females at GER, NAV and LAZ. For the remaining populations, we analyzed differences in body size between sexes using the female BM after oviposition. The analysis of a trade-off between clutch size and egg size was conducted by computing residual scores from the linear regression of CS and ES to female SVL. Population differences in both reproductive traits were analyzed by comparing least squares means once removed the effect of female SVL. Means were compared using post-hoc Scheffé multiple comparison test, at $\alpha=0.05$.

\section{Results}

\section{Geographic variation in body size}

We observed a reduction in size for all morphometric variables measured (SVL, HLR, BM) from the Sierra (PED-AZN), to the Doñana populations (LAZ-RBD) for both species. The greatest size difference observed was between GER and RBD (fig. 2). This variation implied a reduction of $76.1 \%$ in $\mathrm{BM}$ and $35.6 \%$ in SVL (RBD with respect to GER population) in B. calamita. Most of this size reduction occurred among populations adjacent to the transition between granite-schist and sandy soils (differences between GER and JUN accounted for $66.7 \%$ and $47.2 \%$ of the total reduction in BM and SVL, respectively). Therefore, a significant fraction of total reduction occurred within the sandy area of the Doñana area. A similar trend of reduction was displayed by $P$. cultripes populations that showed a decrease of $71.6 \%$ in BM and $36.8 \%$ in SVL (RBD with respect to AZN population). However, $P$. cultripes did not show size reduction within the sandy area of Doñana.

A MANOVA on SVL, BM and RHL showed significant effects of environment (SierraDoñana), population (nested within environment), sex $\times$ environment and sex $\times$ population (environment) interaction, for both species $(P<0.05)$. Univariate ANOVAs showed significant effects of population and sex on SVL, BM and HLR, for both species (table 1).
B. calamita males were significantly bigger and longer than females only in the ABA population (post-hoc comparisons, Scheffé range test, BM: $P<0.001$; SVL: $P=0.017$ ). HLR was sexually dimorphic, males having relatively longer limbs than females throughout all populations $\left(F_{6,584}=178.314, P<0.0001\right)$. Conversely, females tended to be bigger in $P$. cultripes, although significant dimorphism in body size was only found in the AZN population (post-hoc comparisons, Scheffé range test, BM: $P=0.001$; SVL: $P=0.034)$.

The pattern of body size reduction was not parallel between species as indicated by significant species $\times$ population interactions in all morphometric traits (SVL: $F_{5,917}=8.288$, $P<0.001$; BM: $F_{5,805}=14.806, P<0.001$; HLR: $F_{5,890}=11.542, P<0.001$ ) (fig. 2).

\section{Geographic variation in reproductive traits}

MANOVA showed significant effects of population on reproductive traits (CM, ES, CS and RCM) in both species (B. calamita: Wilk's $\lambda=0.226, F_{20,508}=14.333, P<0.001$; P. cultripes: Wilk's $\lambda=0.351, F_{8,90}=7.733$, $P<0.001)$. Univariate ANOVAs showed significant differences among populations in CM, ES and CS in B. calamita and, CM and ES in P. cultripes (B. calamita: CM: $F_{5,219}=36.59$, $P<0.001$; ES: $F_{5,174}=22.192, P<0.001$; CS: $F_{5,216}=19.766, P<0.001 ; P$. cul tripes: CM: $F_{2,70}=21.221, P<0.001$; ES: $F_{2,53}=15.330, P<0.001 ;$ CS: $\left.F_{2,65}=2.324, P=0.105\right)$. Sierra populations of B. calamita showed bigger CS, CM and ES than populations from Doñana (fig. 3). We also found a decrease in mean CM and ES in P. cultripes from Sierra to Doñana populations (fig. 3). Conversely, neither species showed significant differences among populations in RCM (B. calamita: $F_{5,225}=1.963, P=0.085$; $P$. cultripes: $F_{2,70}=2.86, P=0.063$ ). 

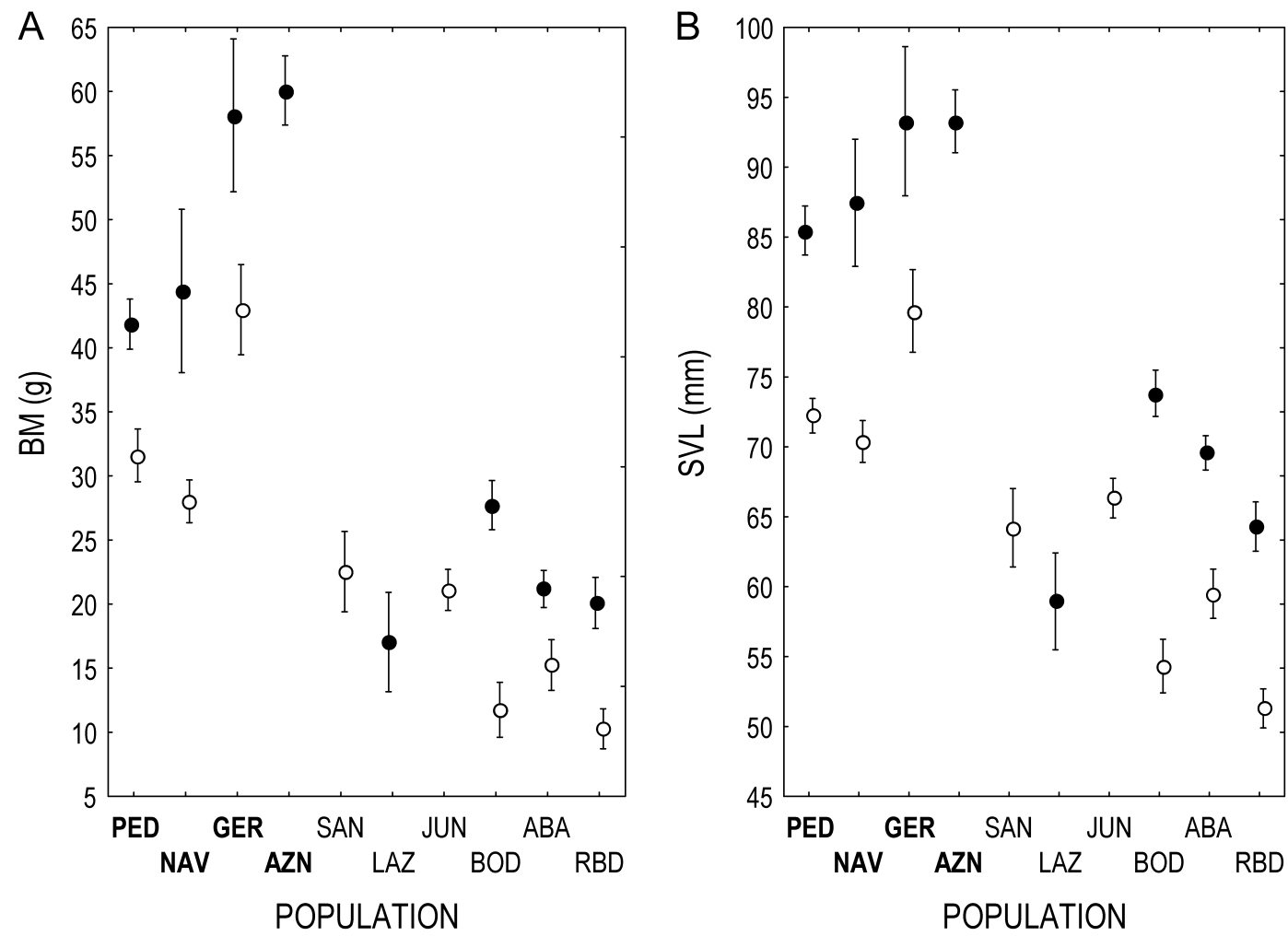

Figure 2. Body size varied greatly among populations. (A) body mass (BM) and (B) snout-vent length (SVL) of Bufo calamita and Pelobates cultripes populations. Values for both sexes are pooled. Solid $=$ Pelobates cultripes, open $=$ Bufo calamita . Populations from the hercinic soils are denoted in bold. All values are means $\pm 1 \mathrm{SE}$.

Table 1. Univariate ANOVA F-values for body size: snout-vent length (SVL), body mass (BM) and hind length right (HLR) of Bufo calamita and Pelobates cultripes. $P$ values: ${ }^{* * *} P<0.001 ; * * P<0.01 ; * P<0.05$. NS: not significant.

\begin{tabular}{|c|c|c|c|c|c|c|}
\hline \multirow[t]{2}{*}{ Source } & \multicolumn{2}{|c|}{ SVL } & \multicolumn{2}{|c|}{$\mathrm{BM}$} & \multicolumn{2}{|c|}{ HLR } \\
\hline & df & $F$ & $\mathrm{df}$ & $F$ & $\mathrm{df}$ & $F$ \\
\hline \multicolumn{7}{|l|}{ B. calamita } \\
\hline Environment & 1 & $620.99^{* * *}$ & 1 & $772.41^{* * *}$ & 1 & $569.91^{* * *}$ \\
\hline Population (environment) & 3 & $29.70^{* * *}$ & 3 & $29.73^{* * *}$ & 3 & $45.92^{* * *}$ \\
\hline Sex & 1 & $9.26^{* *}$ & 1 & $24.58^{* * *}$ & 1 & $140.37^{* * *}$ \\
\hline Sex $\times$ environment & 1 & $5.16^{*}$ & 1 & $4.50^{*}$ & 1 & $10.95^{* *}$ \\
\hline Sex $\times$ population (environment) & 3 & $1.55 \mathrm{NS}$ & 3 & $1.81 \mathrm{NS}$ & 3 & $0.55 \mathrm{NS}$ \\
\hline Error & 483 & & 412 & & 473 & \\
\hline \multicolumn{7}{|l|}{ P. cultripes } \\
\hline Environment & 1 & $360.03^{* * *}$ & 1 & $386.99^{* * *}$ & 1 & $351.00^{* * *}$ \\
\hline Population (environment) & 3 & $24.15^{* * *}$ & 3 & $31.58^{* * *}$ & 3 & $14.88^{* * *}$ \\
\hline Sex & 1 & $18.91^{* * *}$ & 1 & $6.35^{*}$ & 1 & $8.46^{* *}$ \\
\hline Sex $\times$ environment & 1 & $13.38^{* * *}$ & 1 & $22.36^{* * *}$ & 1 & $10.07^{* *}$ \\
\hline Sex $\times$ population (environment) & 3 & $6.35^{* * *}$ & 3 & $5.26^{* *}$ & 3 & $4.24^{* *}$ \\
\hline Error & 415 & & 384 & & 409 & \\
\hline
\end{tabular}



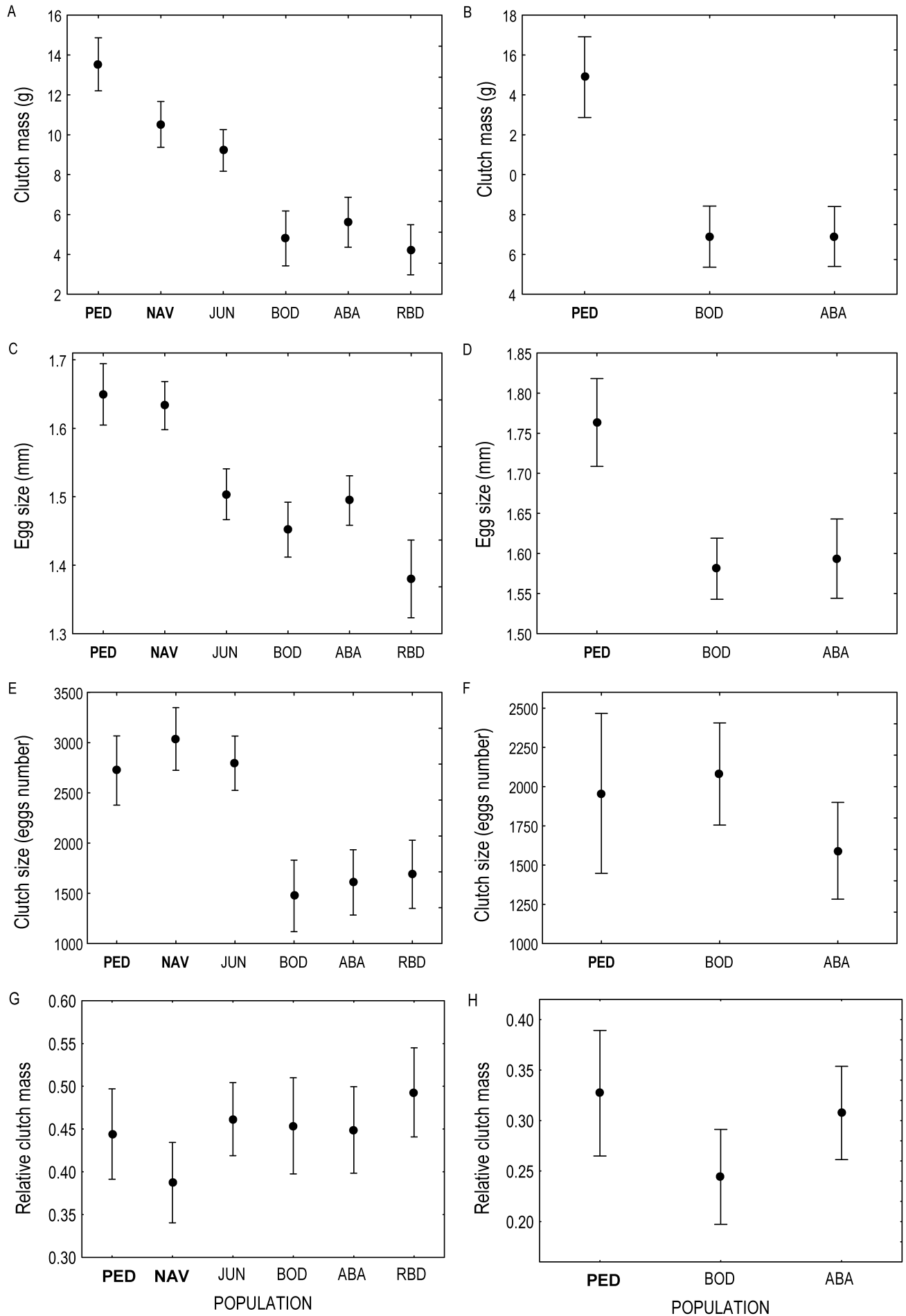

Figure 3. Among-population variation in reproductive traits of Bufo calamita (A, C, E and G) and Pelobates cultripes (B, D, $\mathrm{F}$ and $\mathrm{H}$ ): clutch mass, egg size, clutch size and relative clutch mass. Populations from the hercinic soils are denoted in bold. All values are means \pm 1 SE. Sample sizes: Bufo calamita, PED, $n=34$; NAV, $n=43$; JUN, $n=52$; ABA, $n=37$; BOD, $n=30$; RBD, $n=37$; Pelobates cultripes, PED, $n=16$; ABA, $n=30$; BOD, $n=27$. 
Table 2. Relationships between reproductive variables (clutch size, egg size, clutch mass and relative clutch mass (RCM), and female size: snout-vent length (SVL) and body mass (BM), in Bufo calamita and Pelobates cultripes. All variables were log-transformed. $P$ values: $* * *<0.001$

\begin{tabular}{|c|c|c|c|c|c|c|}
\hline \multirow{2}{*}{$\begin{array}{l}\text { Reproductive traits (y) } \\
\text { vs. body size }\end{array}$} & \multicolumn{3}{|c|}{ Bufo calamita } & \multicolumn{3}{|c|}{ Pelobates cultripes } \\
\hline & $n$ & Equation & $r^{2}$ & $n$ & Equation & $r^{2}$ \\
\hline \multicolumn{7}{|l|}{ Clutch Size } \\
\hline SVL & 229 & $y=2.162+0.257 x$ & $0.502 * * *$ & 73 & $y=0.421+1.626 x$ & $0.233 * * *$ \\
\hline $\mathrm{BM}$ & 215 & $y=5.779+0.655 x$ & $0.551 * * *$ & 73 & $y=5.369+0.632 x$ & $0.311 * * *$ \\
\hline \multicolumn{7}{|l|}{ Egg Size } \\
\hline SVL & 165 & $y=-1.083+0.634 x$ & $0.403 * * *$ & 61 & $y=-0.699+0.271 x$ & $0.229 * * *$ \\
\hline $\mathrm{BM}$ & 165 & $y=0.089+0.116 x$ & $0.401 * * *$ & 61 & $y=0.123+0.104 x$ & $0.250 * * *$ \\
\hline \multicolumn{7}{|l|}{ Clutch Mass } \\
\hline SVL & 226 & $y=-9.067+2.677 x$ & $0.645 * * *$ & 83 & $\mathrm{y}=-11.511+3.126 \mathrm{x}$ & $0.537 * * *$ \\
\hline $\mathrm{BM}$ & 226 & $y=-0.363+0.828 x$ & $0.584 * * *$ & 83 & $y=-1.410+1.038 x$ & $0.519 * * *$ \\
\hline
\end{tabular}

\section{Female size vs. reproductive traits}

ANCOVA revealed that there was no significant 'population $\times$ body size' interactions for any reproductive trait (all $P>0.30$ ). For both species, mean CS, ES, and CM increased significantly with SVL and BM (table 2). Moreover, $\mathrm{CM}$ showed a positive relationship with CS (B. calamita: $r^{2}=0.464, P<0.001, n=214$; $P$. cultripes: $r^{2}=0.326, P<0.001, n=72$ ) and ES (B. calamita: $r^{2}=0.337, P<0.001$, $n=163 ; P$. cultripes: $r^{2}=0.105, P<0.01$, $n=61)$.

\section{Reproductive trade-offs between clutch and egg size}

Size adjusted clutch size showed a significant negative correlation with size adjusted egg size in both species (B. calamita: $r=-0.357$, $P=0.000002, n=167 ;$ P. cultripes: $r=$ $-0.439, P=0.0007, n=56)$. This tradeoff had diverse consequences in the pattern of population variation in reproductive traits. In $P$. cultripes relative fecundities were higher for small sized populations but with the outcome of relative smaller eggs (fig. 4). In B. calamita, there were no differences between larger and smaller-bodied populations in relative fecundities but those populations with higher relative fecundities showed a decrease in relative egg size, with the exception of the PED population (fig. 4).

\section{Discussion}

Geographical variation in body size and reproductive traits

Both $B$. calamita and $P$. cultripes show a striking reduction in body size between populations merely $60 \mathrm{~km}$ apart, in association with a geological transition from hercinic to sandy soils. Such reduction in body size also produced a drastic change in clutch mass, clutch size, and egg size in both species. Average B. calamita body mass of the SAN population, geographically located between Sierra and Doñana and sitting on mixed clay-and-sand soils, was approximately intermediate between populations on either granite-schist or sandy soils, although closer to the masses observed at Doñana (figs 1 and 2). Our sample size for this population is modest, and we lack a quantitative measure of the proportion of sand in the soil, but it could be high enough to explain a higher resemblance of this population to the ones in the sandy area of Doñana than expected from its geographical position.

Variations in life history among anuran populations are often explained by differences in altitude and latitude and related climate (Berven, 1982a,b; Ashton, 2002; Morrison and Hero, 2003; Schäuble, 2004; Laugen et al., 2005). A latitudinal decline in body size has been recently described for $B$. calamita, covering a latitudinal gradient of $2500 \mathrm{~km}\left(38^{\circ}-58^{\circ} \mathrm{N}\right.$; Lesko- 

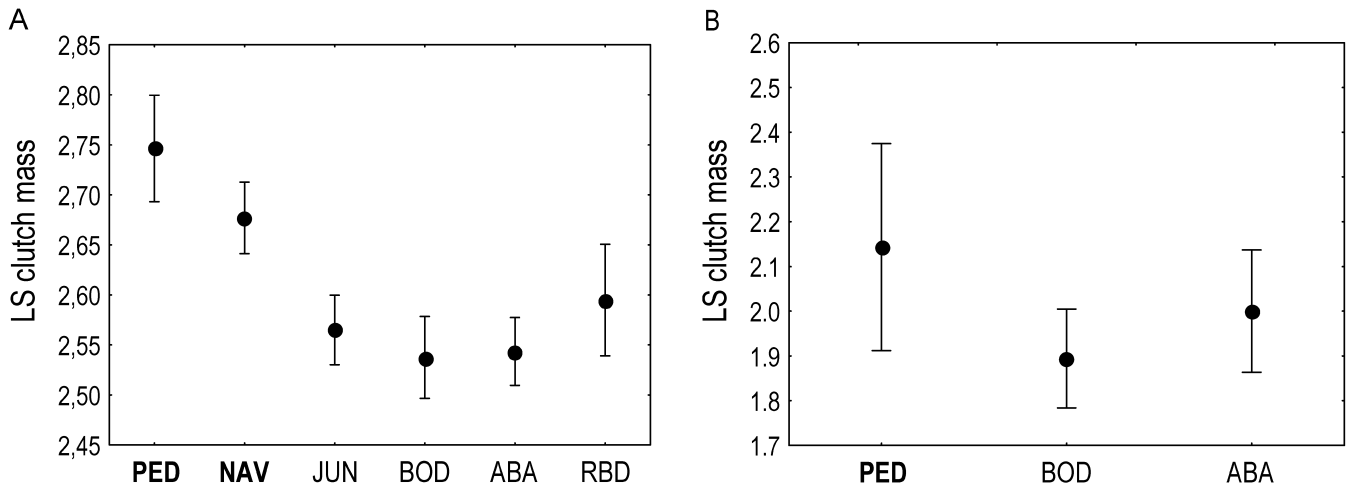

C
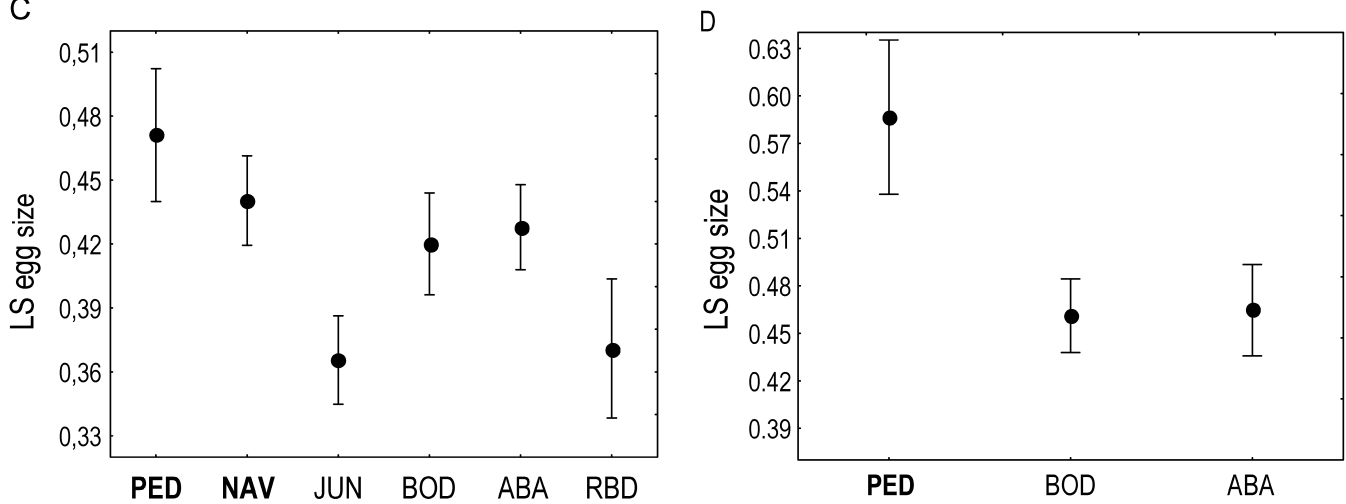

$\mathrm{E}$
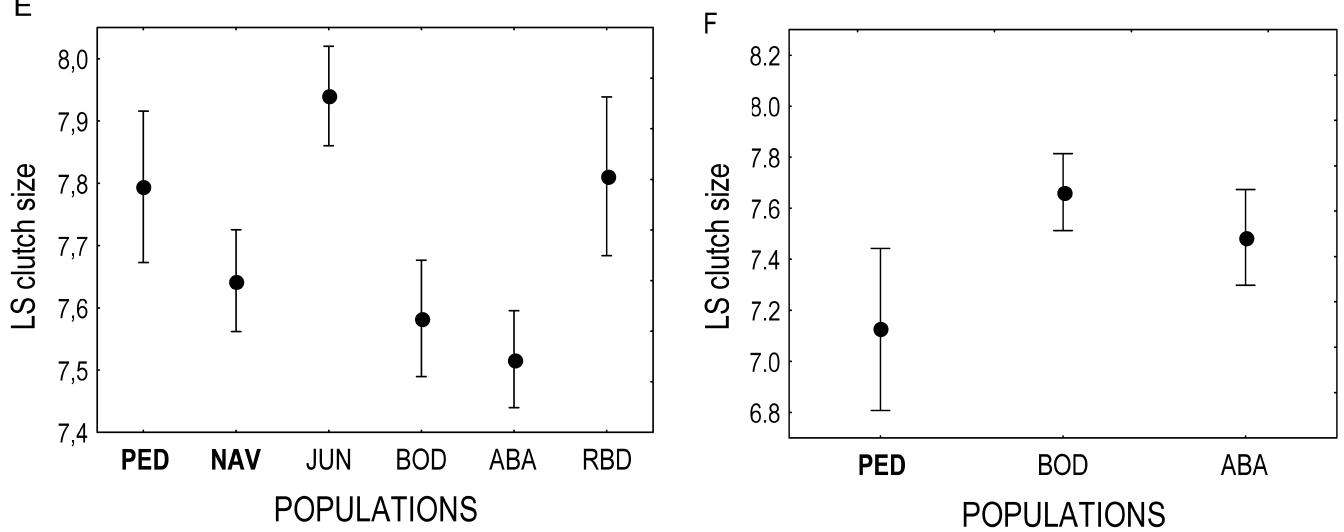

Figure 4. Population variation in size-adjusted clutch mass, egg size and clutch size. The values represent least squares means \pm 1 SE. Left panels correspond to Bufo calamita. Right panels correspond to Pelobates cultripes. Populations from the hercinic soils are denoted in bold. Sample size equivalent to that stated in fig. 3.

var et al., 2006). Mean body size of natterjack toads decreased from south to north, from about $80 \mathrm{~mm}$ (Mas de Melons, Spain) to about $49 \mathrm{~mm}$ (Urmitz, Germany). Surprisingly, we found variation in body size of a similar magnitude abruptly taking place in a much shorter geographic range. Moreover, whereas populations across wide latitudinal ranges experience large climatic differences (Leskovar et al., 2006), our populations differed only in the geological substrates, the climate being virtually identical (fig. 1). In accordance with our observation, two other amphibian species Triturus pygmaeus and Lissotriton boscai exhibit a similar reduction in 
body length (21.4 and $23.5 \%$, respectively) at the sandy soils of Doñana (Díaz-Paniagua et al., 1996; Díaz-Paniagua and Mateo, 1999) in a magnitude equivalent to that found for the two studied toad species. Thus, adaptive or not, there has been a repeated trend towards dwarfism in response to some common environmental factor in some amphibians of the sandy area of Doñana. Comparisons between species with and without size reduction would help to understand the mechanisms behind size variation.

Several non-mutually exclusive factors can contribute to small adult sizes in amphibians: reduced egg size, reduced larval growth, reduced juvenile growth and early sexual maturation. Small females, though, often tend to lay smaller eggs, which in turn tend to yield smaller metamorphs (Bernardo, 1996). Variation in larval growth may affect adult size, especially when compensatory growth does not take place (Metcalfe and Monaghan, 2001). Differences in larval growth may partially explain the divergence found between populations on different substrates, as indicated by common garden experiments (Marangoni and Tejedo, 2008). However, population divergence in size at metamorphosis only accounted for ca. $20 \%$ of total population divergence in adult size (Marangoni and Tejedo, 2008). In amphibians, between 80 and $99.9 \%$ of growth to mature adult size occurs after metamorphosis, in the terrestrial environment (Werner, 1986). Post-metamorphic individuals exhibit indeterminate growth that declines when sexual maturity is attained (Hemelaar, 1988).

Differences in age at maturity and longevity could also account for population divergence if individuals within small-bodied populations matured earlier or exhibited shorter longevities than large-bodied ones (e.g. Bruce and Hairston, 1990). Reduced longevity was suggested as main factor of body size reduction of $P$. cultripes that inhabits sandy substrates of Sierra de Ariça (Portugal) (Leclair et al., 2005). However, our skeletochronological analysis revealed that larger and small-bodied populations did not generally differ in age at maturity or longevity.
Only the RBD population of B. calamita exhibited earlier maturation than the rest, including small-bodied populations from the sandy area (BOD and ABA) (Marangoni, 2006). This difference in age of sexual maturation and shorter lifespan of RBD may explain the variation observed in B. calamita within the sand environment.

The observed changes in body size paralleled changes in reproductive traits in both species such as clutch and egg size, as expected by the positive covariation between female size and reproductive performance (e.g. Berven, 1988). Nonetheless, the relative allocation of reproductive effort to fecundity or to propagule size varied among $B$. calamita populations, even within a given environment. The RBD population showed a higher relative fecundity with relatively smaller eggs, whereas BOD and ABA populations exhibited a reverse trend. Furthermore, the bigger CM and CS observed in JUN with respect to the other Doñana populations could simply be a direct consequence of their large body size, since the size-corrected values of CM did not differ from the other populations, and CS was similar to RBD (fig. 4). Reductions in fecundity may have a clear consequence on fitness via decreasing juvenile recruitment rates (Semlitsch et al., 1996), but small size at metamorphosis decreases the chance for juvenile survival (Reques and Tejedo, 1997; Altwegg and Reyer, 2003; Gomez-Mestre and Tejedo, 2003).

\section{Growing on sandy soils}

The pattern of steep size reduction from hercinic to sandy soils strongly suggests that at least a large fraction of the observed differences in adult size is due to differences in the terrestrial environment. It is clear that sandy soil substrates, directly or indirectly, impose a strong effect on adult body size. Sandy substrates have higher water potential and thus lower water retention than soils with greater proportion of silts or clays. Therefore, sandy soils are highly desiccating substrates that become harsh environments for deficient osmoregulators such as 
amphibians (Ruibal et al., 1969; Packard and Packard, 1988; Cartledge et al., 2006). Desiccating environments would be expected to select for bigger body size because a lower surface-to-volume ratio would help maintaining the water balance. In support of this idea, some authors have found a positive correlation between body size and aridity in some frog species (Nevo, 1973; Rosso et al., 2004). Alternatively, by imposing high energetic costs of maintaining water balance, sandy substrates may constrain growth by reducing activity or foraging efficiency (Rohr and Madison, 2003; Gomez-Mestre and Tejedo, 2005) or, indirectly, by limiting availability of food resources (Rohr, 1997; Bronikowski and Arnold, 1999; Tracy, 1999). The observed dwarfism associated to sandy soils in Doñana contradicts the expected morpho-functional advantage of large size in desiccating substrates and therefore seems to be nonadaptive.

If populations from the sandy soils of the Doñana area are indeed exposed to higher hydric potentials they will have less available water content in their burrowing environment than other populations that occupy less stressful substrates. Drier substrates decrease postmetamorphic growth rate, enhance burying behavior and decrease foraging activity and efficiency in $B$. calamita (Gomez-Mestre and Tejedo, 2005). Likewise, field reciprocal transplant experiments on $P$. cultripes juveniles between sandy and granite-schist soil environments show reduced growth in the sandy environment (Tejedo and Marangoni, unpublished data).

In conclusion, reduced juvenile growth may determine the pattern of body size and reproductive output reduction in the two toad species associated to sandy soils in Doñana. Further analyses are necessary to determine whether other components of the life history such as variation in age at maturity are also contributing to this population divergence.

Acknowledgements. We thank F. Campos and L. Monzón for invaluable help with the field and laboratory work.
D.C. Adams and an anonymous reviewer provided helpful comments on an earlier draft of the manuscript. We thank the Instituto de Recursos Naturales (CSIC) for permission to use their outdoor facilities at the La Hampa agroexperimental field station. This work was supported by grant PB96-0861 from Dirección General de Investigación Científica y Técnica conceded to M. Tejedo. Thanks also to the Consejería de Medio Ambiente de la Junta de Andalucía and the Reserva Biológica de Doñana, for providing the corresponding permits and facilities. All animal experimentation was conducted in accordance with the legal standards of Spain.

\section{References}

Adams, D.C., Church, J.O. (2008): Amphibians do not follow Bergmann's rule. Evolution 62: 413-420.

Altwegg, R., Reyer, H.U. (2003): Patterns of natural selection on size at metamorphosis in water frogs. Evolution 57: 872-882.

Ashton, K.G. (2002): Do amphibians follow Bergmann's rule? Can. J. Zool. 80: 708-716.

Atkinson, D. (1994): Temperature and organism size - a biological law for ectotherms? Adv. Ecol. Res. 25: 1-58.

Atkinson, D., Sibly, R.M. (1997): Why are organisms usually bigger in colder environments? Making sense of a life history puzzle. Trends Ecol. Evol. 12: 235-239.

Bernardo, J. (1996): The particular maternal effect of propagule size, especially egg size: patterns, models, quality of evidence and interpretations. Amer. Zool. 36: 216-236.

Berven, K.A. (1982a): The genetic basis of altitudinal variation in the wood frog Rana sylvatica. I. An experimental analysis of life history traits. Evolution 36: 962-983.

Berven, K.A. (1982b): The genetic basis of altitudinal variation in the wood frog Rana sylvatica. II. An experimental analysis of larval development. Oecologia 52: 360-369.

Berven, K.A. (1988): Factors affecting variation in reproductive traits within a population of wood frogs (Rana sylvatica). Copeia 1988: 605-615.

Bonnet, X., Shine, R., Lourdais, O., Naulleau, G. (2003): Measures of reproductive allometry are sensitive to sampling bias. Funct. Ecol. 17: 39-49.

Bronikowski, A.M., Arnold, S.J. (1999): The evolutionary ecology of life history variation in the Garter Snake Thamnophis elegan. Ecology 80: 2314-2325.

Bruce, R.C., Hairston, N.G. (1990): Life-history correlates of body-size differences between two populations of the salamander, Desmognathus monticola. J. Herpetol. 24: 124-134.

Calder, W.A. (1984): Size, Function and Life History. Boston, Harvard University Press.

Cartledge, V.A., Withers, P.C., Kellie, A., McMaster, K.A., Thompson, G.G., Bradshaw S.D. (2006): Water balance of field-excavated aestivating Australian desert frogs, the cocoon-forming Neobatrachus aquilonius and the noncocooning Notaden nichollsi (Amphibia: Myobatrachidae). J. Exp. Biol. 209: 3309-332. 
Castellano, S., Cucco, M., Giacoma, C. (2004): Reproductive investment of female Green Toads (Bufo viridis). Copeia 2004: 659-664.

Díaz-Paniagua, C. (1986): Reproductive period of amphibians in the biological reserve of Doñana (SW Spain). In: Studies in Herpetology, p. 429-432. Rocek, Z., Ed., Prague, Charles University.

Díaz-Paniagua, C. (1992): Variability in timing of larval season in an amphibian community in SW Spain. Ecography 15: 267-272.

Díaz-Paniagua, C., Mateo, J.A. (1999): Geographic variation in body size and life-history traits in Boca's Newt (Triturus boscai). Herpetol. J. 9: 21-27.

Díaz-Paniagua, C., Mateo, J.A., Andreu, A.C. (1996): Age and size structure of population of Small Marbled Newts (Triturus marmoratus pygmaeus) from Doñana National Park (SW Spain). A case of dwarfism among dwarfs. J. Zool., Lond. 239: 83-92.

Endler, J.A. (1977): Geographic Variation, Speciation, and Cline. Princeton, Princeton University Press.

Fahd, K., Serrano, L., Toja, J. (2000): Crustacean and rotifer composition of temporary ponds in the Doñana National Park (SW Spain) during floods. Hydrobiologia 436: 41-49.

Gomez-Mestre, I., Tejedo, M. (2003). Local adaptation of an anuran amphibian to osmotically stressful environments. Evolution 57: 1889-1899.

Gomez-Mestre, I., Tejedo, M. (2005): Adaptation or exaptation? An experimental test of hypotheses on the origin of salinity tolerance in Bufo calamita. J. Evol. Biol. 18: 847-855.

Gosner, K.L. (1960): A simplified table for staging anuran embryos and larvae with notes on identification. Herpetologica 16: 183-190.

Hemelaar, A. (1988): Age, growth and other population characteristics of Bufo bufo from different latitudes and altitudes. J. Herpetol. 22: 369-388.

Kaplan, R.H. (1998): Maternal effects, developmental plasticity, and life history evolution. In: Maternal Effects as Adaptations, p. 244-260. Mousseau, T.E., Fox, C.W., Eds, New York, Oxford University Press.

Keogh, J.S., Scott, I.A.W., Hayes, C. (2005): Rapid and repeated origin of insular gigantism and dwarfism in Australian Tiger Snakes. Evolution 59: 226-233.

Laugen, A.T., Laurila, A., Jönsson, K.I., Söderman, F., Merilä, J. (2005): Do common frogs (Rana temporaria) follow Bergmann's rule? Evol. Ecol. Res. 7: 717-731.

Leclair, M.H., Leclair Jr., R., Gallant, J. (2005): Application of skeletochronology to a population of Pelobates cultripes (Anura: Pelobatidae) from Portugal. J. Herpetol. 39: 199-207.

Leskovar, C., Oromi, N., Sanuy, D., Sinsch, U. (2006): Demographic life history traits of reproductive Natterjack Toads (Bufo calamita) vary between northern and southern latitudes. Amphibia-Reptilia 27: 365-375.

Lomolino, M.V. (2005): Body size evolution in insular vertebrates: generality of the island rule. J. Biogeogr. 32: 1683-1699.
Marangoni, F. (2006): Variación clinal en el tamaño del cuerpo a escala microgeográfica en dos especies de anuros (Pelobates cultripes y Bufo calamita). Ph.D. Thesis, University of Seville, Spain.

Marangoni, F., Tejedo, M. (2008): Variation in body size and metamorphic traits of Iberian spadefoot toads over a short geographic distance. J. Zool., Lond. 275: 97-105.

McClanahan, L. (1972): Changes in body fluids of burrowed Spadefoot toads as a function of soil water potential. Copeia 1972: 209-216.

Metcalfe, N.B., Monaghan, P. (2001): Compensation for a bad star: grow now, pay later. Trends Ecol. Evol. 16: 255-260.

Morrison, C., Hero, J.M. (2003): Geographic variation in life-history characteristics of amphibians: a review. J. Anim. Ecol. 72: 270-779.

Mousseau, T.A. (1997): Ectotherms follow the converse to Bergmann's rule. Evolution 51: 630-632.

Nevo, E. (1973): Adaptative variation in size of cricket frogs. Ecology 54: 1271-1281.

Packard, G.C., Packard, M.J. (1988): The physiological ecology of reptilian eggs and embryos. In: Biology of the Reptilia, Vol. 16A, p. 523-605. Gans, C., Huey, R.B., Eds, New York, Liss.

Pregill, G. (1986): Body size of insular lizards: a pattern of holocene dwarfism. Evolution 40: 997-1008.

Reques, R., Tejedo, M. (1997): Reaction norms for metamorphic traits in natterjack toads to larval density and pond duration. J. Evol. Biol. 10: 829-851.

Rohr, D.H. (1997): Demographic and life-history variation in two proximate populations of a viviparous skink separated by a steep altitudinal gradient. J. Anim. Ecol. 66: 567-578.

Rohr, J.R., Madison, D.M. (2003): Dryness increases predation risk in efts: support for an amphibian decline hypothesis. Oecologia 135: 657-664.

Rosso, A., Castellano, S., Giacoma, C. (2004): Ecogeographic analysis of morphological and life-history variation in the Italian Treefrog. Evol. Ecol. 18: 303-321.

Ruibal, R., Tevis Jr., L., Roig, V. (1969): The terrestrial ecology of Spadefoot Toad, Scaphiopus hammondii. Copeia 1969: 571-584.

Schäuble, C.S. (2004): Variation in body size and sexual dimorphism across geographical and environmental space in the frogs Limnodynastes tasmaniensis and L. peronii. Biol. J. Linn. Soc. 82: 39-56.

Schmidt-Nielsen, K. (1984): Why Is Animal Size so Important? Cambridge, Cambridge University Press.

Semlitsch, R.D., Scott, D.E., Pechmann, J.H.K., Gibbons, J.W. (1996): Structure and dynamics of and amphibian community: evidence from a 16-year study of a natural pond. In: Long-Term Studies of Vertebrate Communities, p. 217-248. Cody, M.L., Smallwood, J., Eds, San Diego, California, Academic Press.

Shine, R. (1992): Relative clutch mass and body shape in lizards and snakes: is reproductive investment constrained or optimized? Evolution 46: 828-833.

StatSoft. (2001): Statistica (Data analysis software system). Version 6. StatSoft, Tulsa. 
Tejedo, M. (1992): Effects of body size and timing of reproduction on reproductive success in female Natterjack Toads (Bufo calamita). J. Zool., Lond. 228: 545-555.

Tracy, C.R. (1999): Differences in body size among Chuckwalla (Sauromalus obesus) populations. Ecology 80: 259-271.

Van Voorhies, W.A. (1996): Bergmann size clines: a simple explanation for their occurrence in ectotherms. Evolution 50: 1259-1264.
Werner, E. (1986): Amphibian metamorphosis: growth rate, predation risk, and the optimal size at transformation. Am. Nat. 128: 319-341.

Received: March 27, 2008. Accepted: June 26, 2008. 


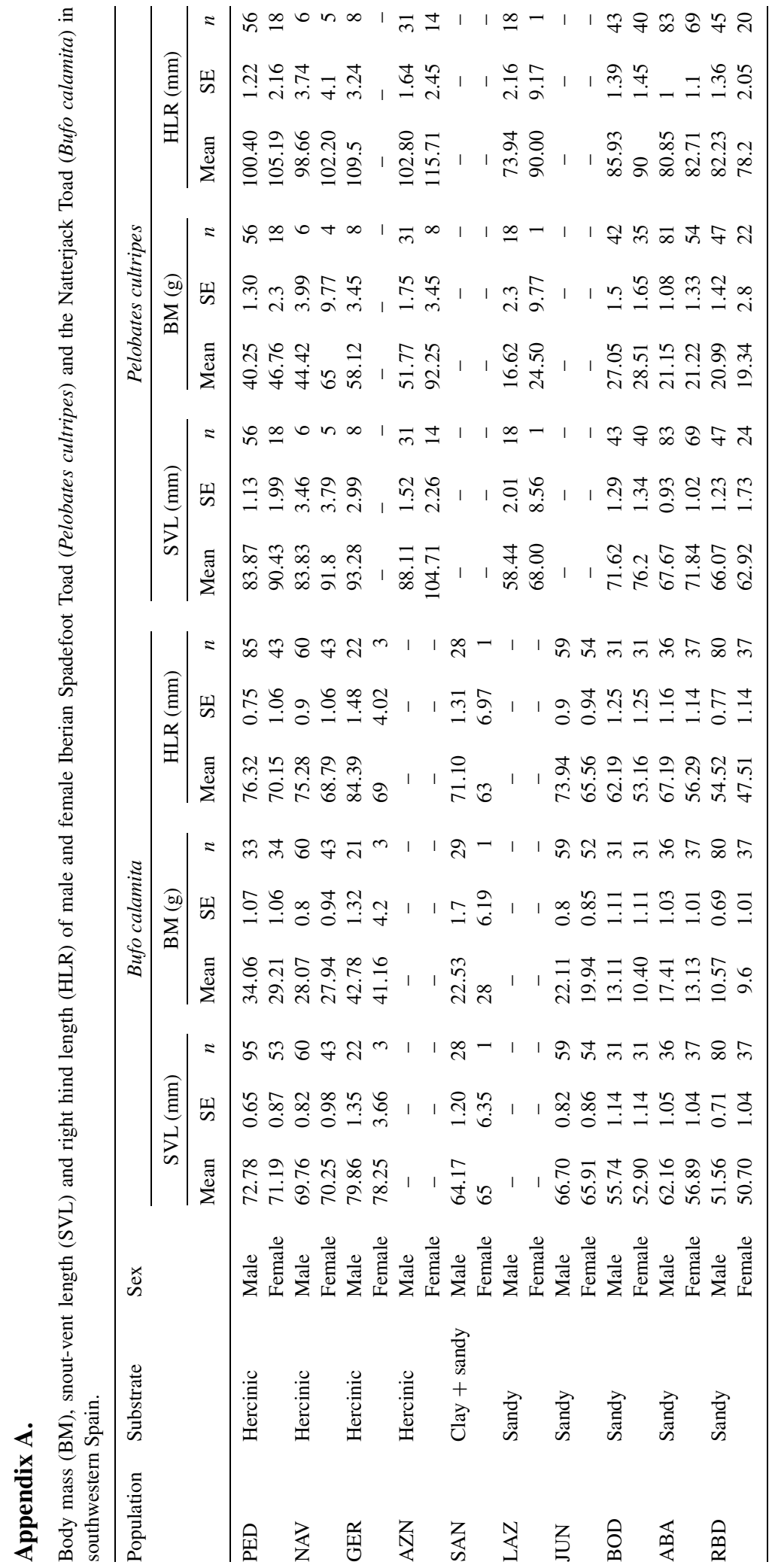

